E. Oetjen - A. Lechleiter - R. Blume •

D. Nihalani · L. Holzman · W. Knepel

\title{
Inhibition of membrane depolarisation-induced transcriptional activity of cyclic AMP response element binding protein (CREB) by the dual-leucine-zipper-bearing kinase in a pancreatic islet beta cell line
}

Received: 28 July 2005 / Accepted: 7 September 2005 / Published online: 21 December 2005

(C) Springer-Verlag 2005

\begin{abstract}
Aims/hypothesis: The activation of the transcription factor cyclic AMP response element binding protein (CREB) by protein kinase $\mathrm{A}$ is inhibited by the human orthologue of the mitogen-activated protein kinase, dualleucine-zipper-bearing kinase (DLK) in teratocarcinoma cells. However, pancreatic beta cells are electrically excitable and a major pathway regulating CREB in these cells is membrane depolarisation, leading to calcium influx and activation of the calcium/calmodulin-dependent protein phosphatase calcineurin. Therefore, the effect of DLK on CREB activity induced by membrane depolarisation was investigated in the beta cell line HIT. Materials and methods: Reporter gene assays and biochemical techniques were used. Results: RT-PCR, Western blot analysis and immunohistochemistry demonstrated the expression of DLK in HIT cells and primary mouse islets. In transient transfection experiments, DLK inhibited both GAL4CREB activity induced by membrane depolarisation, and transcription directed by the CREB binding site, the cyclic AMP response element. Furthermore, DLK inhibited the transcriptional activity conferred by the CREB coactivator, CREB binding protein, both under basal conditions and after membrane depolarisation. DLK was also effective in response to glucose, the most potent physiological stimulus and known to cause membrane depolarisation of beta cells. Inhibition of calcineurin enhanced DLK activity, whereas overexpression of calcineurin reduced the inhibition by DLK of transcription directed by cyclic
\end{abstract}

E. Oetjen $\cdot$ A. Lechleiter $\cdot$ R. Blume $\cdot$ W. Knepel $(\bowtie)$

Molecular Pharmacology, University of Göttingen,

Robert-Koch Str. 40,

37099 Göttingen, Germany

e-mail: wknepel@med.uni-goettingen.de

Tel.: +49-551-395787

Fax: +49-551-395699

D. Nihalani · L. Holzman

Division of Nephrology, Department of Internal Medicine, University of Michigan Medical School,

Ann Arbor, MI, USA
AMP response element after membrane depolarisation. Conclusions/interpretation: These results demonstrate a calcineurin-sensitive inhibition by DLK of CREB activity after membrane depolarisation in pancreatic islet beta cells. This inhibition may, at least partially, be mediated at the coactivator level. The results thus suggest that DLK plays a role in the regulation of beta cell function, including insulin gene transcription and beta cell apoptosis.

Keywords Beta cells · Calcineurin - Cyclic AMP response element binding protein - Dual-leucine-zipperbearing kinase $\cdot$ Membrane depolarisation

Abbreviations CBP: CREB binding protein - CRE: cyclic AMP response element - CREB: cyclic AMP response element binding protein - DLK: dual-leucinezipper-bearing kinase $\cdot$ ERK: extracellular signal-regulated kinase · GST: glutathione $S$-transferase · JIP: c-Jun $\mathrm{N}$-terminal kinase interacting protein $\cdot J \mathrm{NK}$ : c-Jun $\mathrm{N}$-terminal kinase $\cdot$ MAPK: mitogen-activated protein kinase - MAPKKK: mitogen-activated protein kinase kinase kinase $\cdot$ ZPK: zipper protein kinase

\section{Introduction}

Pancreatic islet beta cells synthesise and secrete the peptide hormone insulin and are thus essential for glucose homeostasis, with beta cell dysfunction leading to diabetes mellitus. Among the multiple factors required for normal beta cell function is the transcription factor cyclic AMP response element binding protein (CREB) [1-5].

CREB is ubiquitously expressed and couples diverse signalling pathways to gene expression $[6,7]$. Through its basic region leucine zipper domain CREB binds as a dimer to genes that carry CREB binding sites with the consensus core octamer motif 5'-TGACGTCA-3' (cyclic AMP response element [CRE]). The transcriptional activity of CREB is markedly induced by various signalling pathways, such as those activated by cyclic AMP, calcium, extracel- 
lular signal-regulated kinase (ERK1/2) and p38 mitogenactivated protein kinase (MAPK) through the phosphorylation of CREB on Ser119 (in CREB-327, corresponding to Ser133 in CREB-341) [6, 7]. This phosphorylation allows CREB to interact with its coactivator CREB binding protein (CBP) [7, 8], which then mediates CREB transcriptional activity to the general transcription machinery $[7,8]$. CREB has been shown to play a pivotal role in many different physiological and developmental functions, such as learning and memory [7], drug addiction [9], T cell development and activation [7], growth factor-dependent cell survival [7] and neurodegeneration [10]. It is also involved in the regulation of glucose homeostasis. CREB participates in glucose homeostasis by stimulating glucose production in the liver [11] and activating glucagon gene transcription in pancreatic islet alpha cells [12]. In pancreatic islet beta cells CREB maintains beta cell function by binding to and activating the insulin gene $[1-4,13]$, as well as by inhibiting apoptosis and promoting beta cell survival [5].

In the NIH3T3 and in a human teratocarcinoma cell line, protein kinase A-induced CREB activity was inhibited by the mitogen-activated protein kinase kinase kinase (MAPKKK) zipper protein kinase (ZPK), possibly by a direct interaction between CREB and ZPK [14]. However, the effect of ZPK on CREB activity in pancreatic islet beta cells was unknown. Furthermore, beta cells are electrically excitable, and a major pathway that regulates CREB in these cells is closure of ATP-dependent potassium channels and membrane depolarisation, leading to calcium influx through voltage-dependent L-type calcium channels and activation of the calcium/calmodulin-dependent protein phosphatase calcineurin $[3,4,12,15-17]$. Therefore, in the present study the effect of dual-leucine-zipper-bearing kinase (DLK), the mouse orthologue of ZPK [18], on CREB activity induced by membrane depolarisation was investigated in the beta cell line HIT.

\section{Materials and methods}

\section{Plasmid constructs}

The plasmids p4xSomCRELuc [2], 5xGal4E1BLuc [3], and the expression vectors for DLK and DLKmt [19], calcineurin subunits A and B [20], GAL4-CBP, containing the C-terminal amino acids of CBP from 1,678 to 2,441 (kind gift of R. H. Goodman, Oregon Health and Sciences University, Portland, OR, USA) [8] have been described before. The expression vector for glutathione $S$-transferase (GST)-c-Jun (amino acids 1-135) was kindly provided by M. Kracht, Medical School Hanover, Hanover, Germany [21]. For GAL4-CREB a fragment encoding full length CREB-327 was amplified by PCR using 5'-ATATAG GATCCGTATGACCATGGAATCTGGA-3' and 5'-ACGC GGAGCTCTTAATCTGATTTGTGGCAGT-3' as up- and downstream primers, respectively. The plasmid RSVCREB [22] served as template. The PCR product was cloned into the BamHI and SacI sites of pSG424 [23]. All constructs were confirmed by sequencing.
Cell culture and transfection of DNA

HIT-T15 cells [12] were grown in RPMI 1640 medium supplemented with $10 \%$ FCS, $5 \%$ horse serum, penicillin $(100 \mathrm{U} / \mathrm{ml})$ and streptomycin $(100 \mu \mathrm{g} / \mathrm{ml})$. Cells were transfected by the DEAE-dextran method [12] with indicator plasmid and expression vector as indicated. Cotransfections were carried out with a constant amount of DNA, which was maintained by addition of Bluescript (Stratagene, La Jolla, CA, USA). To check for transfection efficiency $1 \mu \mathrm{g}$ cytomegalovirus-green fluorescent protein (plasmid CMV-GFPtpz) per 6-cm dish was cotransfected. Cell extracts were prepared $48 \mathrm{~h}$ after transfection. Cells were stimulated by membrane depolarisation with $\mathrm{KCl}$ ( $40 \mathrm{mmol} / \mathrm{l}) 6 \mathrm{~h}$ before harvest. In the experiments using high glucose stimulation, the cells were incubated after transfection in medium containing $0.4 \mathrm{mmol}$ glucose/1; for stimulation with high glucose, the glucose concentration was raised to $20 \mathrm{mmol} / 124 \mathrm{~h}$ before harvest. The activities of luciferase and green fluorescent protein were determined as described previously $[12,24]$.

Western blot analysis

HIT cells were harvested in lysis buffer (Tris $10 \mathrm{mmol} / \mathrm{l}$, $\mathrm{pH} 7.4$, Triton X-100 1\%, Nonidet P-40 $0.5 \%, \mathrm{NaCl}$ $150 \mathrm{mmol} / 1$, sodium fluoride $20 \mathrm{mmol} / \mathrm{l}$, sodium orthovanadate $0.2 \mathrm{mmol} / 1$, EGTA $1.0 \mathrm{mmol} / \mathrm{l}$, EDTA $1.0 \mathrm{mmol} / \mathrm{l}$, phenylmethylsulfonyl fluoride $0.2 \mathrm{mmol} / \mathrm{l})$. Cells were incubated for $10 \mathrm{~min}$ at room temperature in $100 \mu \mathrm{l}$ lysis buffer per 6-cm dish, scraped from the dish and passed ten times through a 26-gauge needle. Lysates were then centrifuged at $16,000 \mathrm{~g}$ for $20 \mathrm{~min}$ at room temperature. Laemmli gel loading buffer (Tris- $\mathrm{HCl} 62.5 \mathrm{mmol} / \mathrm{l}, \mathrm{pH} 6.8$, SDS $2 \%$, glycerol $10 \%$, $\beta$-mercaptoethanol $5 \%$, bromphenol blue $0.5 \%$ ) was added to the supernatant, the samples were boiled, subjected to SDS-PAGE $(5.5 \%$ gel $)$ and transferred to a nitrocellulose membrane. The membrane was incubated in 5\% fat-free dried milk in TRIS-buffered saline Tween (Tris-HCl $25 \mathrm{mmol} / \mathrm{l}, \mathrm{pH}$ 7.4, $\mathrm{NaCl}$ $137 \mathrm{mmol} / \mathrm{l}, \mathrm{KCl} 5 \mathrm{mmol} / \mathrm{l}, \mathrm{CaCl}_{2} 0.7 \mathrm{mmol} / \mathrm{l}, \mathrm{MgCl}_{2}$ $0.1 \mathrm{mmol} / \mathrm{l}$, Tween $200.2 \%$ ) for $2 \mathrm{~h}$ at room temperature and then with fresh Tris-buffered saline Tween supplemented with antibody against DLK [18] in a 1:2,000 dilution overnight at $4^{\circ} \mathrm{C}$. Before and after incubation with the secondary antibody the membrane was washed four times for $10 \mathrm{~min}$, each time in Tris-buffered saline Tween. Antibody-antigen complex was detected with ECL reagents (Amersham Biosciences UK, Little Chalfont, Bucks, UK).

\section{RT-PCR}

Total RNA was extracted from HIT cells and from isolated islets of NMRI mice [4] using a commercial kit (RNeasy, Qiagen, Hilden, Germany). For first-strand cDNA synthesis, random hexamer primers (Amersham Biosciences) were used. The RT enzyme was obtained from Invitrogen 
(Superscript II reverse transcriptase; Carlsbad, CA, USA). For PCR amplification the following primers were used: upstream primer, 5'-CCCAAGC-TTGGGAAGTCCCCTT TGAGG-3'; and downstream primer, 5'-GGCGAGCTC.C AAAATCTGAGATCTTCACC-3', the dots marking the beginning of DLK coding sequence (size of the expected product: $432 \mathrm{bp}$ ). PCR without the RT step served as control for DNA contamination; PCR using the DLK encoding expression vector as template served as control for the size.
Immunohistochemistry

Frozen 5- $\mu \mathrm{m}$ sections from mouse pancreas were cut in a cryostat at $-20^{\circ} \mathrm{C}$ and mounted. Sections were fixed by chloroform-acetone, dried at room temperature, and rehydrated by placing in a wet chamber for $30 \mathrm{~min}$ and by incubation with PBS for a further $30 \mathrm{~min}$. All subsequent steps were carried out in a wet chamber. Sections were incubated overnight at $4{ }^{\circ} \mathrm{C}$ with an antibody against DLK [18] (1:50 dilution), washed four times with PBS and
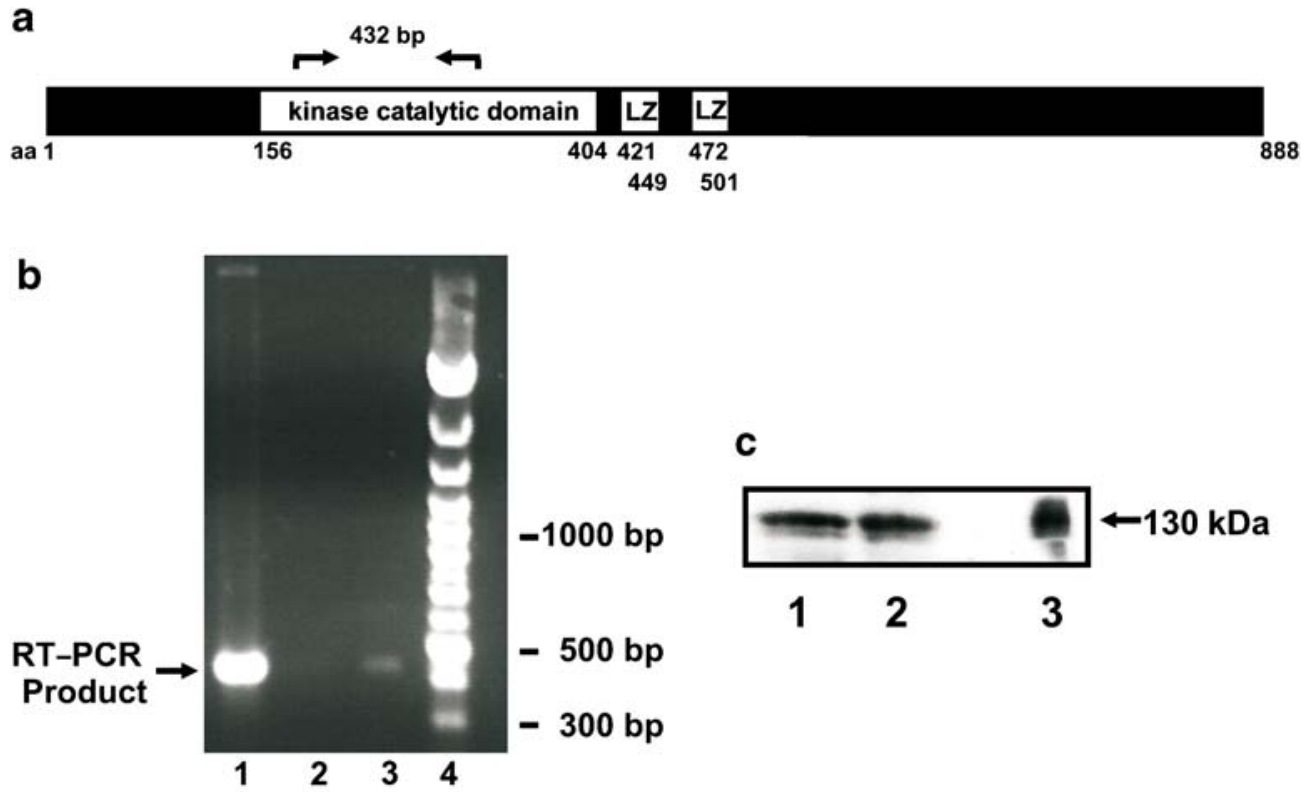

C
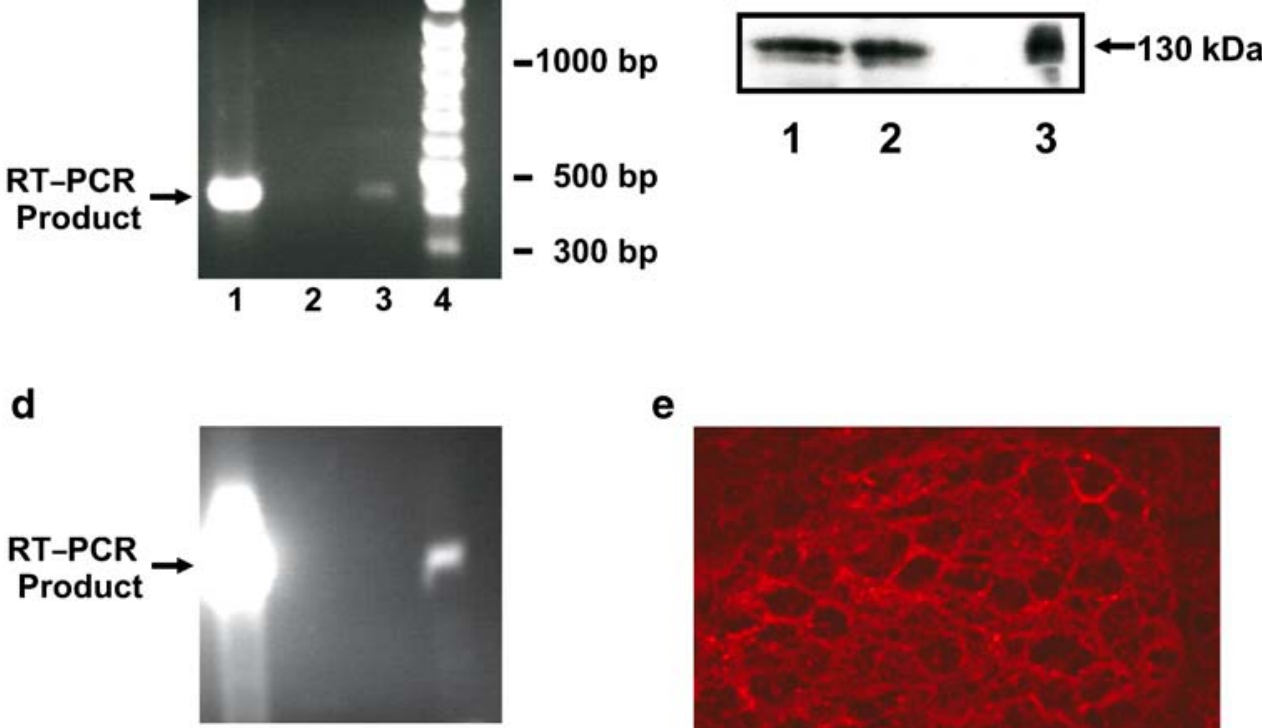

$\begin{array}{llll}1 & 2 & 3 & 4\end{array}$

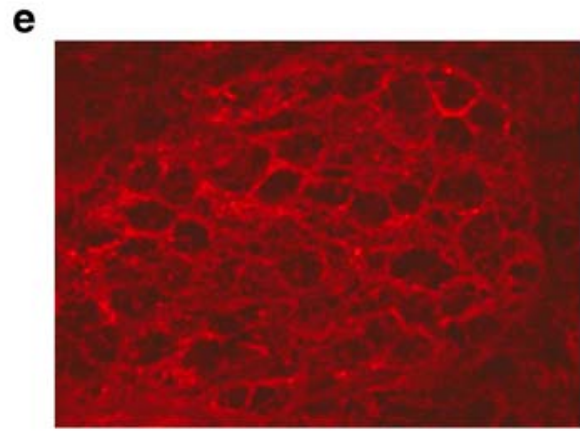

\section{anti-DLK}

Fig. 1 DLK is expressed in the insulin-producing pancreatic islet beta cell line HIT $(\mathbf{a}-\mathbf{c})$ and in primary mouse islets $(\mathbf{d}-\mathbf{e})$. a Sketch of DLK indicating the relative position of the primers and the size of the expected fragment. b RT-PCR of DLK transcripts. An RT-PCR product of the expected size was obtained as shown by agarose gel electrophoresis (lane 3). Lane 1, PCR using the expression vector for DLK as template; lane 2, PCR reaction with total RNA but omission of the RT enzyme; lane 4, molecular size markers. c Western blot. Whole HIT cell extract was subjected to immunoblotting. Lanes 1 and 2, a band corresponding to the size of DLK; lane 3, $2 \mu \mathrm{g}$ of the expression vector for DLK were transiently transfected into HIT cells,

whole cell extract was prepared $48 \mathrm{~h}$ after transfection, and a small portion was subjected to immunoblotting to serve as a control. d RTPCR of DLK transcripts from isolated mouse islets (lane 4). Lane 1, PCR using the expression vector for DLK as template; lane 2, PCR reaction without template; lane 3, PCR reaction with total RNA but omission of the RT enzyme. e Immunohistochemistry of mouse pancreas. Primary mouse islets are stained by an anti-DLK antibody. Note that cells throughout the islets are stained, indicating the expression of DLK in insulin-producing beta cells. No staining was seen when the first antibody was omitted (specificity control) (not shown). Magnification: $\times 400$ 

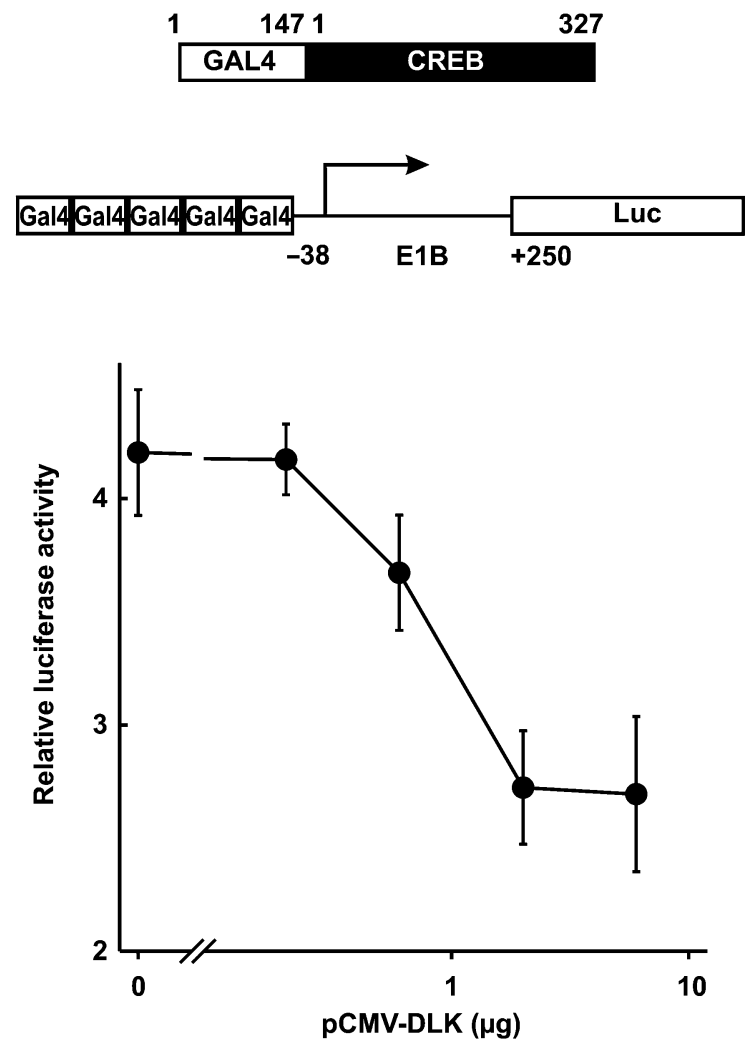

Fig. 2 Inhibition by DLK of CREB-directed transcription after membrane depolarisation. The plasmid $5 \times$ Gal4E1BLuc $(2 \mu \mathrm{g})$ was cotransfected with an expression vector for a GAL4-CREB fusion protein $(2 \mu \mathrm{g})$ and with $0.2,0.6,2$ and $6 \mu \mathrm{g}$ of an expression vector for wild-type DLK. Cells were stimulated with $\mathrm{KCl}(40 \mathrm{mmol} / \mathrm{l}) 6 \mathrm{~h}$ before harvest. Luciferase activity is expressed relative to the mean value in each experiment of the activity measured in the respective controls without $\mathrm{KCl}$ treatment. Values are means $\pm \mathrm{SEM}$ of three independent experiments, each done in duplicate

a

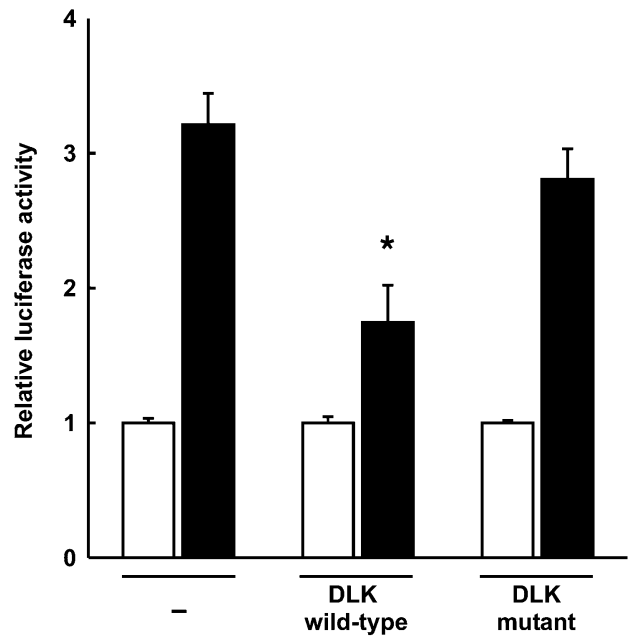

Fig. 3 Effect of DLK and a DLK mutant on CREB-directed transcription after membrane depolarisation (a) or after cyclic AMP treatment $(\mathbf{b})$. The plasmid $5 \times$ Gal4E1BLuc $(2 \mu \mathrm{g})$ was cotransfected with GAL4-CREB $(2 \mu \mathrm{g})$ and $2 \mu \mathrm{g}$ of Bluescript (minus sign) or $2 \mu \mathrm{g}$ of the expression vector for wild-type DLK (DLK wild-type) or DLK K185A (DLK mutant) as indicated. Cells were treated with incubated with a tetramethyl rhodamine isothiocyanatelabelled anti-rabbit antibody for $15 \mathrm{~min}$ at room temperature. After washing four times with PBS the sections were dehydrated by increasing ethanol concentrations. DLK was visualised by a Leica microscope DM5000D using Leica FW400 software (Leica, Solms, Germany).

\section{In vitro kinase assay}

Cells were treated $48 \mathrm{~h}$ after transfection with cyclosporin A $(5 \mu \mathrm{mol} / \mathrm{l})$ or tacrolimus $(167 \mathrm{nmol} / \mathrm{l})$ for $30 \mathrm{~min}$ and harvested to prepare whole-cell extract. Briefly, dishes were washed once with ice-cold PBS, cells were scraped into Eppendorf tubes and washed with ice-cold PBS. The supernatant fraction was discarded and the pellet was resuspended in $50 \mu \mathrm{l}$ special lysis buffer (Tris $10 \mathrm{mmol} / \mathrm{l}$, $\mathrm{pH} 7.05$, sodium pyrophosphate $30 \mathrm{mmol} / \mathrm{l}, \mathrm{NaCl} 50 \mathrm{mmol} /$ 1, Triton X-100 1\%, $\mathrm{Na}_{3} \mathrm{VO}_{4} 2 \mathrm{mmol} / \mathrm{l}, \mathrm{NaF} 50 \mathrm{mmol} / \mathrm{l}, \beta-$ glycerophosphate $20 \mathrm{mmol} / \mathrm{l}$, supplemented with phenyl methyl suphonyl fluoride $0.5 \mathrm{mmol} / 1$, leupeptin $0.5 \mu \mathrm{g} / \mathrm{ml}$, pepstatin $0.5 \mu \mathrm{g} / \mathrm{ml}$, ocadaic acid $400 \mathrm{nmol} / \mathrm{l})$. Cells were incubated on ice for $20 \mathrm{~min}$ and centrifuged $(10,000 \mathrm{~g}$, $15 \mathrm{~min}, 4^{\circ} \mathrm{C}$ ). The protein content in the supernatant fraction was determined according to Bradford [25]. Lysates were stored at $-80^{\circ} \mathrm{C}$. The in vitro kinase assay using $30 \mu \mathrm{g}$ protein and GST-c-Jun as substrate was performed as described previously [21]. The amount of phosphorylated GST-c-Jun was determined by a PhosphorImager Bas Reader 1500 (Fuji Photo Film, Tokyo, Japan) using TINA 2.0 software (Raytest, Straubenhardt, Germany).

b

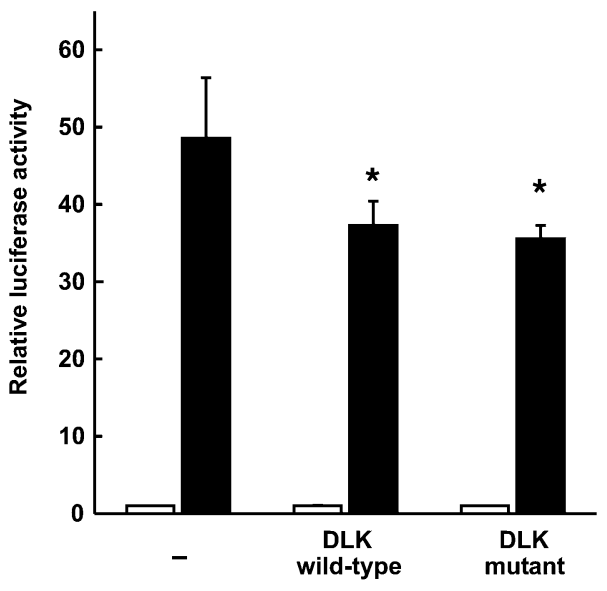

$\mathrm{KCl}$ (40 mmol/l; black bars) (a) or the adenylate cyclase activator forskolin (10 $\mu \mathrm{mol} / \mathrm{l}$; black bars) (b) for $6 \mathrm{~h}$ before harvest. Luciferase activity is expressed relative to the mean value in each experiment of the activity measured in the respective controls without $\mathrm{KCl}$ or forskolin treatment. Values are means \pm SEM of three independent experiments each done in duplicate. ${ }^{*} p<0.05$ vs control 
Materials

Luciferin was purchased from PJK Industrievertretungen (Kleinblittersdorf, Germany); glutathione agarose beads and forskolin were purchased from Sigma (Taufkirchen, Germany). Cyclosporin A was provided by Novartis Pharma (Basel, Switzerland); tacrolimus (FK506) by Fujisawa (Osaka, Japan). A stock solution of cyclosporin A $(10 \mathrm{mg} / \mathrm{ml})$ was prepared in ethanol with $20 \%$ Tween 80 and further diluted in RPMI. Forskolin was dissolved in DMSO, and tacrolimus in ethanol. Controls received the solvent only.

\section{Statistical analysis}

All results are expressed as means \pm SEM. Statistical significance was calculated with the Wilcoxon test for paired samples for non-parametric distribution. A value of $p<0.05$ was considered significant.

\section{Results}

Expression of DLK in the pancreatic islet beta cell line HIT and in primary mouse islets

DLK has been reported to be expressed in a tissue-specific fashion with by far the highest levels in the brain and lower levels in the kidney and lung [18]. Its expression in pancreatic islets has not yet been examined. Using the pancreatic islet beta cell line HIT, a band of the expected size was detected by RT-PCR and Western blot analysis (Fig. 1a), indicating that DLK is expressed in this pancreatic islet beta cell line. In addition, the expression

Fig. 4 Inhibition by DLK of CRE-directed transcription. a Effect of DLK on CRE-directed transcription after membrane depolarisation. The plasmid p4xSomCRELuc $(2 \mu \mathrm{g})$ was transiently cotransfected with $0.2,0.6,2$ and $6 \mu \mathrm{g}$ of an expression vector for wild-type DLK. Cells were stimulated with $\mathrm{KCl}(40 \mathrm{mmol} / \mathrm{l})$ for $6 \mathrm{~h}$ before harvest. Luciferase activity is expressed relative to the mean value in each experiment of the depolarisation-induced activity measured in the controls (no DLK). Values are means \pm SEM of three independent experiments, each done in duplicate. ${ }^{*} p<0.05$ vs control. b Effect of DLK and its mutant on CRE-directed transcription after membrane depolarisation. The plasmid p4xSomCRELuc $(2 \mu \mathrm{g})$ was transiently cotransfected with $0.2 \mu \mathrm{g}$ of Bluescript (minus sign) or $0.2 \mu \mathrm{g}$ of an expression vector for wild-type DLK (DLK wild-type) or mutant DLK (DLK mutant). KCl-stimulated cells, black bars. Luciferase activity is expressed relative to the mean value in each experiment of the activity measured in the respective controls without $\mathrm{KCl}$ treatment. Values are means \pm SEM of four independent experiments, each done in duplicate. ${ }^{*} p<0.05$ vs control. $\mathbf{c}$ Effect of DLK and its mutant on CRE-directed transcription after cyclic AMP treatment. Plasmid cotransfection, as panel (b) with the exception that $2 \mu \mathrm{g}$ of plasmid were used. Cells were stimulated with the adenylate cyclase activator forskolin $(10 \mu \mathrm{mol} / \mathrm{l}$; black bars $)$ for $6 \mathrm{~h}$ before harvest. Luciferase activity is expressed relative to the mean value in each experiment of the activity measured in the respective controls without forskolin treatment. Values are means \pm SEM of four independent experiments, each done in duplicate. ${ }^{*} p<0.05$ vs control a
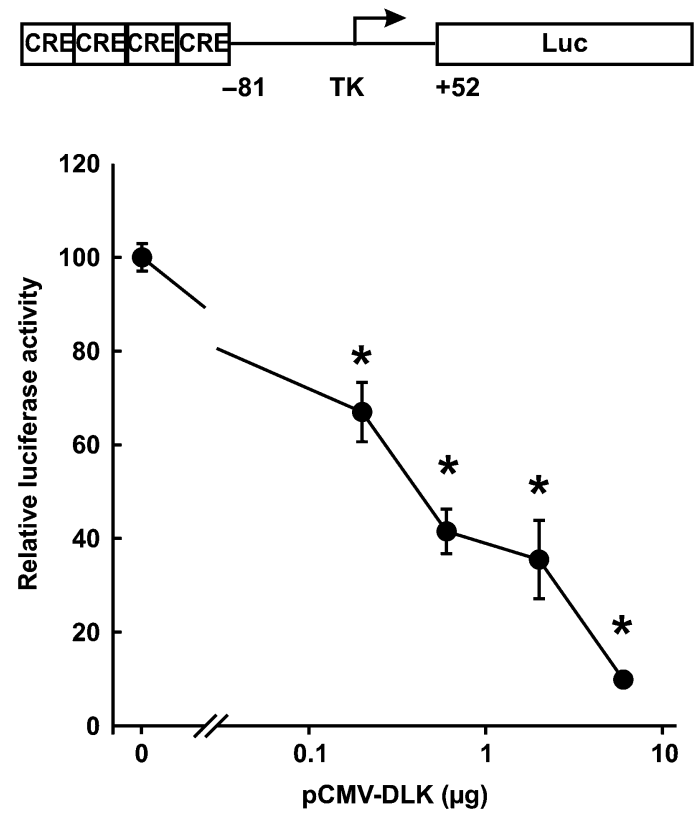

b

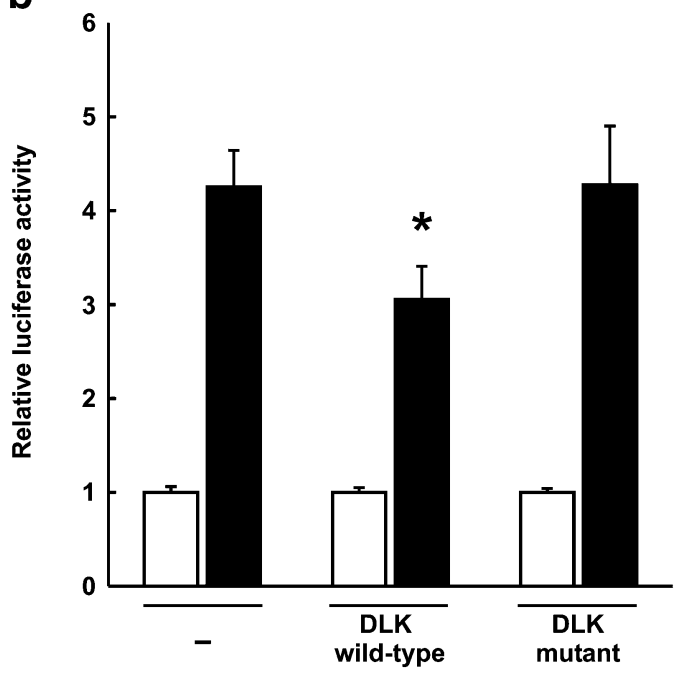

C

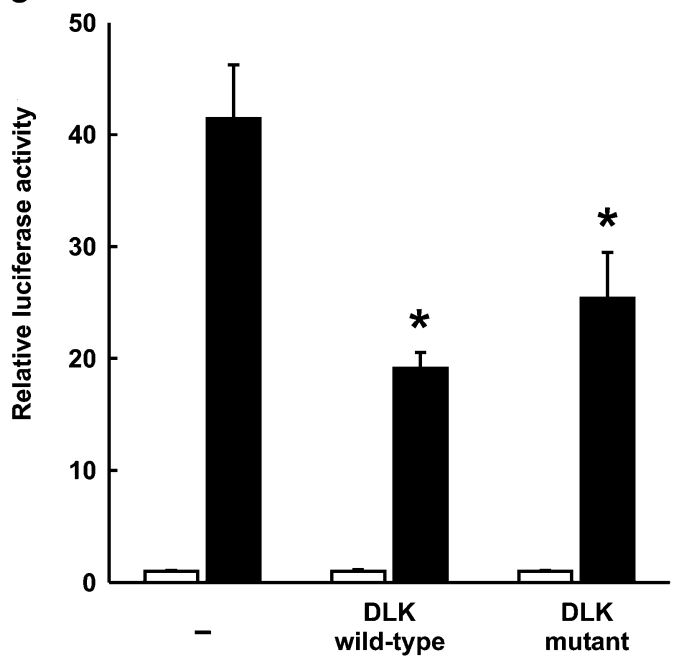


of DLK in primary mouse islets was demonstrated by RTPCR and immunohistochemistry (Fig. 1b).

Inhibition by DLK of membrane depolarisationinduced CREB activity in HIT beta cells

To examine the effect of DLK on membrane depolarisation-induced CREB transcriptional activity in the beta cell line, the GAL4 system was used. An expression vector encoding CREB fused to the DNA binding domain of the yeast transcription factor GAL4 was transfected into HIT cells together with a luciferase reporter gene that is directed by five copies of the GAL4 DNA-binding site placed in front of a minimal viral E1B promoter (Fig. 2, upper panel). High-potassium-induced membrane depolarisation stimulated CREB activity about four-fold (Fig. 2). The cotransfection of increasing amounts of an expression vector for DLK caused an inhibition of membrane depolarisationinduced CREB activity (Fig. 2). The maximum inhibition was about $45 \%$ (Fig. 2). DLK had no effect on basal activity (results not shown). To test whether the kinase activity of DLK is required for the effect of DLK, a DLK kinase-dead mutant was employed in which the exchange of Lys 185 to Ala within the ATP-binding domain abolishes DLK kinase activity $[19,26]$. As shown in Fig. 3a, membrane depolarisation-induced CREB activity was inhibited by wild-type DLK but not by the DLK mutant, indicating that the effect of DLK is specific and depends on its kinase activity. CREB activity induced by the adenylate cyclase activator forskolin was also reduced by cotransfection of the DLK expression vector (Fig. 3b), consistent with the previous study in NIH3T3 and NT2 teratocarcinoma cells [14]. However, in contrast to stimulation by membrane depolarisation (Fig. 3a), forskolin-induced CREB activity was also reduced by the DLK kinase-dead mutant (Fig. 3b). Taken together, the data demonstrate that DLK inhibited CREB activity induced by membrane depolarisation in the pancreatic islet beta cell line.

Fig. 5 DLK inhibits the transcriptional activity of the CREB coactivator CBP under basal conditions and after membrane depolarisation. a The plasmid $5 \times$ Gal4E1BLuc $(2 \mu \mathrm{g})$ was cotransfected with an expression vector for GAL4-CBP C-terminus $(2 \mu \mathrm{g})$ and with $0.2,0.6,2$ and $6 \mu \mathrm{g}$ of the expression vector for wild-type DLK. Cells were left untreated (closed circles) or treated with $\mathrm{KCl}$ $(40 \mathrm{mmol} / \mathrm{l}$; open circles) $6 \mathrm{~h}$ before harvest. Luciferase activity is expressed relative to the mean value in each experiment of the activity measured in the respective controls without $\mathrm{KCl}$ and without DLK. Values are means \pm SEM of three independent experiments each done in duplicate. b Effect of DLK and its mutant on the transcriptional activity of CBP. The plasmid 5xGal4E1BLuc $(2 \mu \mathrm{g})$ was cotransfected with an expression vector for GAL4-CBP $(2 \mu \mathrm{g})$ and with $0.6 \mu \mathrm{g}$ of Bluescript (minus sign) or $0.6 \mu \mathrm{g}$ of the expression vector for wild-type DLK (DLK wild-type) or DLK K185A (DLK mutant) as indicated. Luciferase activity is expressed relative to the mean value in each experiment of the activity measured in the respective controls (no $\mathrm{KCl}$, no DLK). Values are means \pm SEM of four independent experiments each done in duplicate. ${ }^{*} p<0.05$ vs control
Inhibition by DLK of CRE-directed transcription after stimulation by membrane depolarisation in HIT beta cells

Although other CRE-binding transcription factors, such as ATF-2, are known [6], CREB has been shown previously to be the nuclear protein, in extracts from the beta cell line HIT, that binds to the CRE; it has also been shown to confer cyclic AMP and membrane depolarisation responsiveness to the CRE in these beta cells [1-4]. To examine whether CREB thus confers DLK responsiveness to the CRE in pancreatic islet beta cells, a CRE-luciferase reporter gene was used.

a
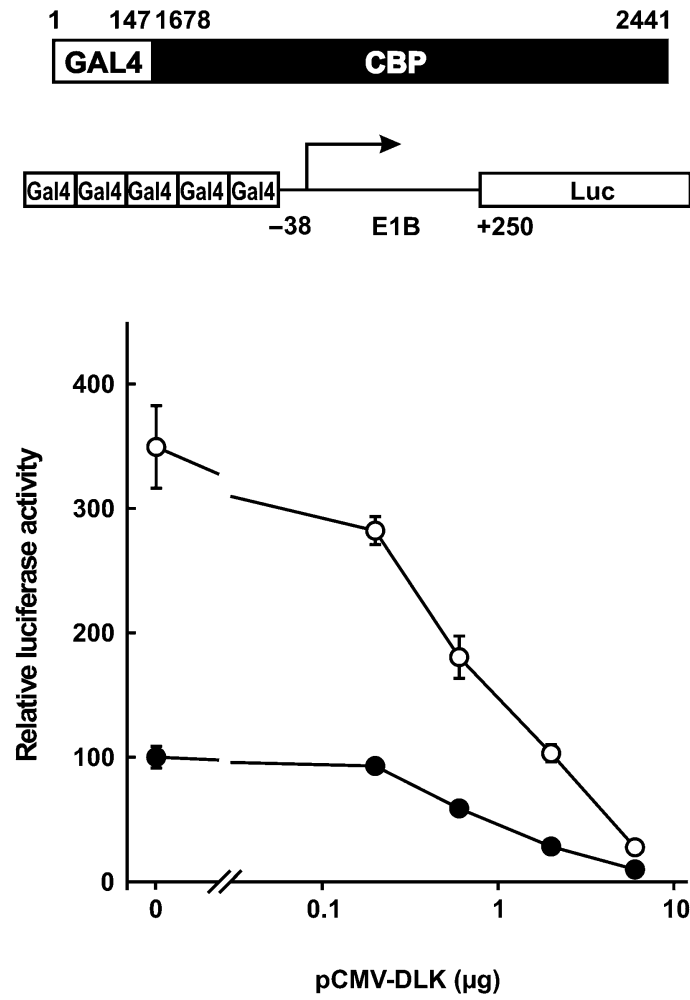

b

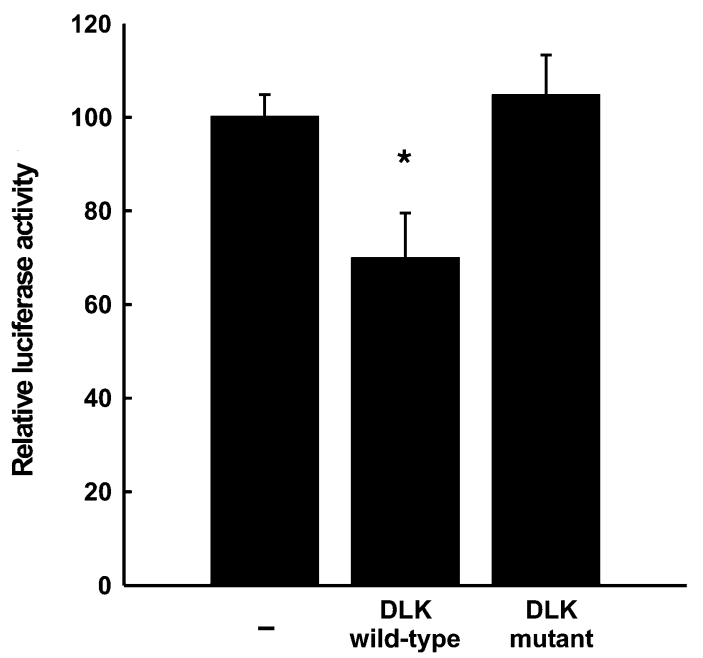


Membrane depolarisation stimulated CRE-directed transcription $4.2 \pm 0.6$-fold $(n=6)$ in the beta cell line HIT. The cotransfection of increasing amounts of the DLK expression vector markedly inhibited membrane depolarisation-induced CRE transcriptional activity (Fig. 4a), whereas the kinasedead DLK mutant was inactive (Fig. $4 b$ ). When a greater amount of the expression vectors $(2 \mu \mathrm{g}$ per dish compared with $0.2 \mu \mathrm{g}$ in Fig. 4b) was used, DLK inhibited depolarisation-induced CRE activity by $86 \pm 4 \% \quad(p<0.05)$, whereas the kinase-dead DLK mutant produced no effect ( $n=8$ each). In contrast, forskolin-induced CRE activity was inhibited by both DLK and mutant DLK (Fig. 4c), similar to forskolin-induced CREB activity (Fig. 3b). These results demonstrate that after stimulation by membrane depolarisation, CREB as well as CRE transcriptional activity is inhibited by DLK kinase activity in the beta cell line HIT.

Inhibition by DLK of the transcriptional activity of CBP in HIT beta cells

CREB transcriptional activity is generally thought to be transmitted to the general transcription machinery through the CREB coactivator CBP, which is recruited by CREB after phosphorylation at Ser119 (in CREB-327) [7, 8]. CBP is a large modular protein, and its C-terminus is known to exhibit strong transcriptional activity and to exert regulatory functions $[8,27]$. To examine whether DLK may have an effect on CBP, a GAL4-CBP C-terminus (amino acids $1,678-2,441)$ fusion protein was used together with the GAL4-luciferase reporter gene (Fig. 5a, top). Membrane depolarisation stimulated GAL4-CBP activity 3.5-fold (Fig. 5a). Cotransfection of increasing amounts of DLK

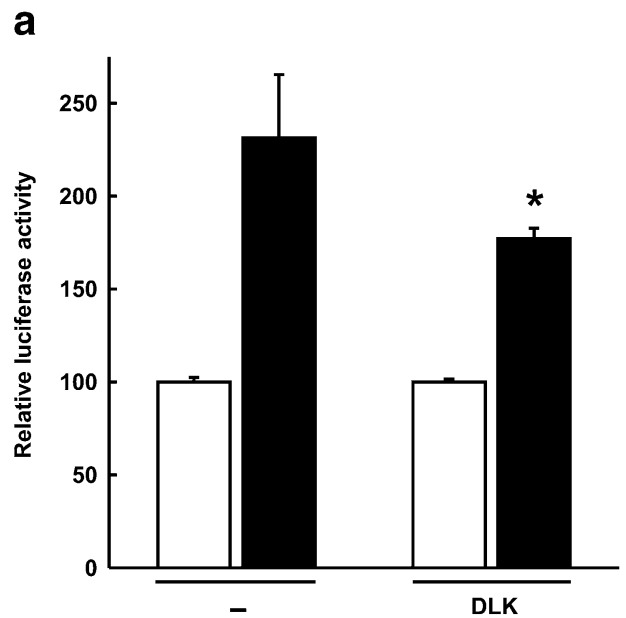

Fig. 6 DLK inhibits CRE and CBP transcriptional activity induced by glucose. a CRE-mediated transcription. The plasmid p4xSomCRELuc $(2 \mu \mathrm{g})$ was transiently cotransfected with $2 \mu \mathrm{g}$ of Bluescript (minus sign) or $2 \mu \mathrm{g}$ of an expression vector for wildtype DLK (DLK). Cells were stimulated by high glucose $(20 \mathrm{mmol} /$ 1; black bars) as indicated. Luciferase activity is expressed relative to the mean value in each experiment of the activity measured in the respective controls (low glucose). Values are means \pm SEM, $n=6$. ${ }^{*} p<0.05$ vs high glucose without DLK. b CBP transcriptional produced a marked inhibition of GAL4-CBP transcriptional activity both under basal conditions and after stimulation by membrane depolarisation (Fig. 5a). The kinase-dead DLK mutant was inactive (Fig. 5b). These data demonstrate that DLK kinase activity inhibits CBP activity and thereby suggest that DLK may, at least in part, inhibit depolarisation-induced CREB transcriptional activity in pancreatic islet beta cells at the coactivator level.

Inhibition by DLK of CRE/CREB and CBP transcriptional activity in response to glucose

Glucose is the most potent physiological stimulus for pancreatic islet beta cells and is known to cause membrane depolarisation $[15,28]$. Use of high glucose as a more physiological stimulus for membrane depolarisation enhanced CRE- and CBP-dependent transcription about 2.3-fold (Fig. 6). Cotransfection of DLK inhibited this glucoseinduced transcriptional activity (Fig. 6). These data suggest that DLK inhibits CRE-mediated gene transcription to a similar degree when membrane depolarisation is effected by more physiological approaches.

Calcineurin sensitivity of the inhibition by DLK in HIT beta cells

In aggregating neuronal-glial cultures, the inhibition by cyclosporin A of the calcium/calmodulin-dependent protein phosphatase calcineurin prevented a membrane depolarisation-induced shift in the electrophoretic mobility of DLK [19], suggesting that the phosphorylation state of DLK may

b

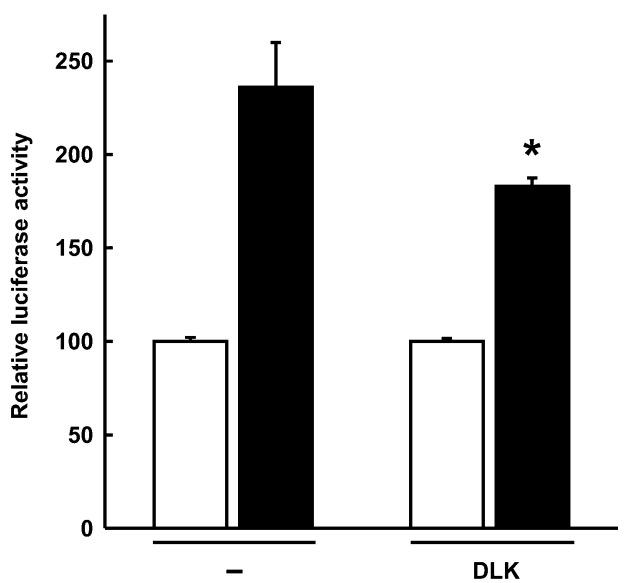

activity. The plasmid $5 \times$ Gal4E1BLuc $(2 \mu \mathrm{g})$ was cotransfected with an expression vector for GAL4-CBP $(2 \mu \mathrm{g})$ and with $2 \mu \mathrm{g}$ of Bluescript (minus sign) or $2 \mu \mathrm{g}$ of the expression vector for wildtype DLK (DLK). Cells were stimulated by high glucose $(20 \mathrm{mmol} /$ 1; black bars) as indicated. Luciferase activity is expressed relative to the mean value in each experiment of the activity measured in the respective controls (low glucose). Values are means \pm SEM, $n=6$. $* p<0.05$ vs high glucose without DLK 
a

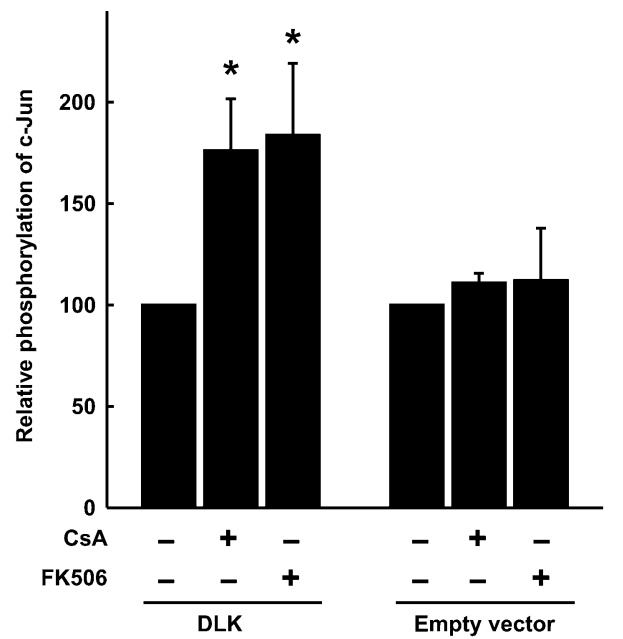

Fig. 7 DLK activity is calcineurin-sensitive. a The calcineurin inhibitors cyclosporin A (CsA) and tacrolimus (FK506) enhance DLK-dependent c-Jun phosphorylation. HIT cells were transiently transfected with an expression vector for DLK or the empty vector $(6 \mu \mathrm{g}$ each). After $48 \mathrm{~h}$ cells were treated with CsA $(5 \mu \mathrm{mol} / \mathrm{l})$ or FK506 (167 nmol/1) for $30 \mathrm{~min}$ as indicated. Whole-cell extracts were prepared and an in vitro kinase assay was performed using GST-c-Jun (amino acids 1-135) as substrate. Phosphorylation of cJun is expressed relative to the phosphorylation of c-Jun in the absence of treatment. Values are means \pm SEM of six independent experiments. ${ }^{*} p<0.05$ vs control. b Overexpression of calcineurin $(\mathrm{CN})$ attenuated the inhibitory effect of DLK on CRE-directed

be regulated by calcineurin. In order to investigate whether the DLK kinase activity is regulated by calcineurin in the pancreatic islet beta cell line HIT, an ex vivo assay was performed. As a MAPKKK, DLK is known to activate the cJun N-terminal kinase (JNK), whose activity can be measured in cell lysates [21]. HIT cells were transfected with the DLK expression vector or the empty vector and JNK activity was measured in cell lysates using GST-c-Jun as substrate. As shown in Fig. 7a, treatment of HIT cells with two chemically distinct inhibitors of calcineurin, cyclosporin A and tacrolimus, enhanced JNK activity only in DLKtransfected cells, suggesting that inhibition of calcineurin increases DLK activity in this beta cell line. The lack of effect of cyclosporin A and tacrolimus in cells transfected with the empty vector (Fig. 7a) may be due to the sensitivity of the assay used that is insufficient to detect endogenous DLK activity.

In view of the evidence that DLK kinase activity is regulated by calcineurin in HIT cells (Fig. 7a), the calcineurin sensitivity of the inhibition by DLK of CRE/ CREB-directed transcription was examined next. As shown in Fig. 7b, the inhibition by DLK of membrane depolarisation-induced CRE transcriptional activity was diminished after overexpression of calcineurin $(p<0.05)(n=6)$. These data further support the view that DLK kinase activity and thus the inhibition by DLK of depolarisation-induced CRE/ CREB transcriptional activity is calcineurin-sensitive. b

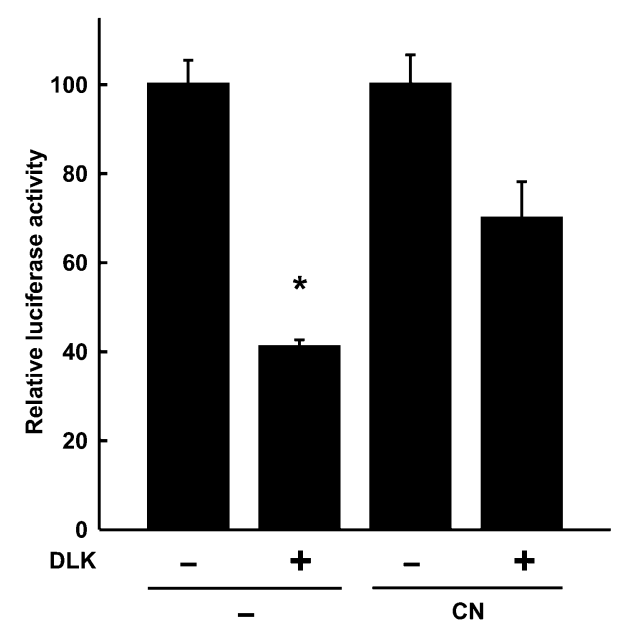

transcription after membrane depolarisation. The plasmid $\mathrm{p} 4 \times$ SomCRELuc $(1 \mu \mathrm{g})$ was transiently cotransfected with $2 \mu \mathrm{g}$ of an expression vector for wild-type DLK (DLK), or $2 \mu \mathrm{g}$, each, of the expression vectors for the $\mathrm{CN}$ subunits $\mathrm{A}$ and $\mathrm{B}$ or $4 \mu \mathrm{g}$ of empty vector (minus sign) or DLK plus $\mathrm{CN}$ as indicated. Cells were treated with $\mathrm{KCl}(40 \mathrm{mmol} / \mathrm{l})$ for $6 \mathrm{~h}$ before harvest. Luciferase activity is expressed relative to the mean value in each experiment of the respective control treated with $\mathrm{KCl}$ (no DLK). Values are means \pm SEM of three independent experiments each done in duplicate. ${ }^{*} p<0.05$, comparing inhibition by DLK in absence and presence of $\mathrm{CN}$

\section{Discussion}

Feeding triggers a series of hormonal and nutrient cues that act on pancreatic islet beta cells to promote insulin release, insulin gene transcription and beta cell survival $[15,28]$. Elevations in blood glucose provide the most potent stimulus. Upon its uptake into beta cells, glucose oxidation in the pancreatic beta cell induces closure of $\mathrm{K}_{\mathrm{ATP}}$ channels, membrane depolarisation, calcium entry via voltage-sensitive L-type calcium channels, and consequent phosphorylation and thus activation of the transcription factor CREB [5, 15, 29], which is essential for beta cell function [1-5]. Two mechanisms for linking membrane depolarisation-induced elevations of intracellular calcium to the activation of CREB have been proposed, mostly based on studies in neuronal systems. First, calcium itself may enter the nucleus and activate nuclear CaM kinase IV and lead to phosphorylation of CREB on Ser119. This may hold true shortly after depolarisation [30]. Alternatively, calcium may act locally near the membrane and close to the mouth of the L-type voltage-dependent calcium channel. A model has been proposed in which calcium binds calmodulin tethered to the channel, causing it to associate with the IQ motif of the channel; this association then leads to the activation of the Ras-mitogen-activated extracellular signal-regulated kinase kinase-ERK1/2 MAPK signalling pathway and sustained CREB Ser119 phosphorylation 
$[30,31]$. In addition to these kinases, the calcium/ calmodulin-dependent protein phosphatase calcineurin is also required for CREB activation by membrane depolarisation $[3,16,17]$. The present study now demonstrates that, in contrast to the stimulation by ERK1/2, another member of the MAPK signalling pathways, DLK, can negatively regulate membrane depolarisation-induced CREB activity in a beta cell line.

DLK is a serine/threonine kinase and belongs to the mixed-lineage kinases that function as MAPKKK [18, 32]. As such, DLK phosphorylates and activates the dualspecificity MAPKK MKK7 and MKK4, which in turn phosphorylate and activate the MAPK JNK [26, 33, 34]. Cterminal of the kinase domain DLK has two leucine zipper motifs that mediate protein dimerisation by forming coiledcoil structures [18]. However, within the cell and under basal conditions, DLK is associated with the scaffold proteins JNK interacting protein (JIP) [34-36] and Plenty of SH3 [36], which assemble and facilitate the activation of the DLK-dependent JNK module. JIP maintains DLK in a monomeric, unphosphorylated, inactive state $[35,36]$. It is assumed that signals promoting the dissociation of DLK from JIP lead to homodimerisation of DLK via its leucine zipper domains, followed by its autophosphorylation and activation [35-37]. Thus the overexpression of DLK also results in its activation [34]. The present study demonstrates that DLK is expressed in the insulin-producing pancreatic islet beta cell line HIT and in primary mouse islets including beta cells. It shows furthermore that, after overexpression and thus activation, DLK inhibits membrane depolarisation-induced CREB transcriptional activity through its kinase activity in the beta cell line. The inhibition by DLK is conferred to the CRE by CREB (present study), which has been shown previously to be the nuclear protein in HIT beta cells that binds to the CRE and mediates membrane depolarisation responsiveness of the CRE [1-4].

In NIH3T3 and NTera-2 teratocarcinoma cell lines the overexpression of the human orthologue of DLK, ZPK, has been shown to inhibit CREB activity after stimulation by protein kinase A [14], which is confirmed by the present study in HIT beta cells. However, in contrast to stimulation by membrane depolarisation, protein kinase A-induced CREB activity was inhibited also by the kinase-dead mutant of DLK (present study), suggesting that the mechanism of inhibition by DLK may differ depending on the stimulus used. ZPK is able to interact directly with CREB and to phosphorylate a CREB peptide that contains the CREB leucine zipper domain [14]. Although the functional consequences, if any, of these effects of DLK are unknown, they raise the possibility that protein kinase A might allow DLK-CREB interaction, which may interfere with CREB transactivation independently of the DLK kinase activity. Our results suggest another site of action for DLK after stimulation of CREB by membrane depolarisation, namely the CREB coactivator CBP.

In addition to the phosphorylation on Ser119, CREB transcriptional activity is regulated by membrane depolarisation-induced signalling pathways at additional steps of
CREB-mediated transcriptional activation [7, 27]. It was thought initially that the CREB coactivator CBP confers constitutive transcriptional activity to promoter-bound CREB. Meanwhile, it became clear that membrane depolarisation-induced calcium influx regulates not only CREB phosphorylation at Ser119 and thus the recruitment of CBP [7, 29], but also targets CBP directly. Consistent with previous studies in the mouse pituitary cell line AtT20 [27], in cortical neurons [38], in hippocampal neurons [39] and in HIT beta cells [24], the present study confirms that membrane depolarisation stimulates CBP transcriptional activity. It demonstrates furthermore that DLK through its kinase activity markedly inhibits CBP transcriptional activity both under basal conditions and after stimulation by membrane depolarisation. Several kinases have been shown to activate $\mathrm{CBP} / \mathrm{p} 300$, including calcium/calmodulin-dependent kinase IV, MAPKKK1 and ERK1/2 [27, 3941]. As shown in the present study, DLK is the first example of a kinase that inhibits CBP transcriptional activity. Taken together, our findings suggest that DLK inhibits membrane depolarisation-induced CREB activity by acting, at least in part, on the CREB coactivator CBP. This inhibition by DLK appears to be subjected to regulation by calcineurin phosphatase.

Calcineurin is a calcium/calmodulin-dependent serine/ threonine protein phosphatase that is activated by membrane depolarisation-induced calcium influx and is inhibited specifically by the immunosuppressive drugs cyclosporin A and tacrolimus [42]. In aggregating neuronal-glial cultures, depolarisation of plasma membrane led to dephosphorylation of DLK that was blocked by cyclosporin A, suggesting that the phosphorylation state of DLK is regulated by membrane depolarisation via calcineurin [19]. Consistent with the view that lack of autophosphorylation renders DLK enzymically inactive [34], DLK kinase activity was shown in the present study to be enhanced by cyclosporin A and tacrolimus, which are known to inhibit calcineurin phosphatase activity with high potency also in pancreatic islet beta cells $[4,16,17,29]$. On the other hand, overexpression of calcineurin decreased the inhibition by DLK of membrane depolarisation-induced CRE/CREB transcriptional activity. When taken together, these data suggest that calcineurin regulates the phosphorylation state and the kinase activity of DLK and thereby counteracts the inhibition by DLK of depolarisationinduced CREB activity at the level of the CREB coactivator CBP. In addition to the regulation of DLK activity, other mechanisms exist through which calcineurin can influence JNK [43-45].

Interestingly, it has been shown previously that cyclosporin A and tacrolimus inhibit CRE-directed transcription after stimulation by membrane depolarisation-induced calcium influx in beta cells without decreasing the phosphorylation of CREB on Ser119 [3, 4, 16, 17, 29]. Several lines of evidence suggest that this inhibition by cyclosporin A and tacrolimus is mediated via calcineurin $[3,4,16,17$, 29] and, at least in part [46], takes place at the level of the CREB coactivator CBP [24]. In view of the findings of the present study that (1) DLK kinase activity is calcineurin- 
sensitive, and that (2) DLK inhibits depolarisation-induced CREB and CBP transcriptional activity, there is a possibility that, in addition to the Transducer of regulated CREB activity [46], DLK may be another calcineurin substrate involved in the stimulation of CREB transcriptional activity by membrane depolarisation and its inhibition by the immunosuppressive drugs cyclosporin $\mathrm{A}$ and tacrolimus. However, the part, if any, of DLK in these responses is unknown and remains to be demonstrated.

Several lines of evidence suggest that the regulation by DLK of depolarisation-induced CREB/CRE activity may play a critical role in beta cell function. A major stimulus that causes membrane depolarisation in pancreatic islet beta cells is glucose, and the present study shows that DLK inhibits also glucose-induced CREB/CRE transcriptional activity. Glucose increases calcineurin phosphatase activity and insulin gene transcription in normal beta cells [3, 4]. The human insulin gene carries four copies of the CRE and is regulated by CREB [3, 4]. In addition to the activation of insulin gene transcription, CREB is essential for beta cell survival, since mice expressing a dominant-negative CREB mutant develop diabetes mellitus secondary to beta cell apoptosis [5]. Whereas activation of the MAPK ERK1/2 has been linked to cell survival, DLK is generally linked to induction of apoptosis [32, 47]. Studies in neuronal systems indicate that DLK might be an important kinase that mediates growth-factor-deprivation-induced neuronal apoptosis $[32,47]$. DLK may function similarly in the electrically excitable pancreatic islet beta cells. DLK is thought to be activated by cellular stress and inflammatory cytokines [32, 35]. Reactive oxygen species that are formed under these conditions [48] are likely to inhibit glucose-induced calcineurin phosphatase activity in beta cells $[42,49]$, thus further promoting DLK kinase activity. It is tempting to speculate that DLK kinase activity may then compromise beta cell function through inhibition of $\mathrm{CBP} / \mathrm{CREB}$ activity and a consequent decrease in insulin synthesis and induction of beta cell apoptosis. Consistent with this view, the downregulation or mutation of the DLKbinding scaffold protein JIP1 has been shown to lead to decreased insulin gene expression, higher susceptibility to apoptotic stimuli and diabetes mellitus [50, 51].

Acknowledgements We thank our colleagues F. Vetterlein (Department of Anaesthesiological Research, University of Göttingen) and P. Hülper (Children's Hospital, Paediatrics I, University of Göttingen) for their valuable and generous advice and help in performing the immunohistochemical analysis. This work was supported by a grant from the Deutsche Forschungsgemeinschaft SFB 402 (A3).

\section{References}

1. Eggers A, Siemann G, Blume R, Knepel W (1998) Gene-specific transcriptional activity of the insulin cAMP-responsive element is conferred by NF-Y in combination with cAMP response element-binding protein. J Biol Chem 273:18499-18508

2. Oetjen E, Diedrich T, Eggers A, Eckert B, Knepel W (1994) Distinct properties of the cAMP-responsive element of the rat insulin I gene. J Biol Chem 269:27036-27044
3. Oetjen E, Grapentin D, Blume R et al (2003) Regulation of human insulin gene transcription by the immunosuppressive drugs cyclosporin A and tacrolimus at concentrations that inhibit calcineurin activity and involving the transcription factor CREB. Naunyn Schmiedebergs Arch Pharmacol 367:227-236

4. Oetjen E, Baun D, Beimesche S et al (2003) Inhibition of human insulin gene transcription by the immunosuppressive drugs cyclosporin A and tacrolimus in primary, mature islets of transgenic mice. Mol Pharmacol 63:1289-1295

5. Jhala US, Canettieri G, Screaton RA et al (2003) cAMP promotes pancreatic $\beta$-cell survival via CREB-mediated induction of IRS2. Genes Dev 17:1575-1580

6. Habener JF, Miller CP, Vallejo M (1995) cAMP-dependent regulation of gene transcription by cAMP response elementbinding protein and cAMP response element modulator. Vitam Horm 51:1-57

7. Mayr B, Montminy M (2001) Transcriptional regulation by the phosphorylation-dependent factor CREB. Nat Rev/Mol Cell Biol 2:599-609

8. Kwok RPS, Lundblad JR, Chrivia JC et al (1994) Nuclear protein CBP is a coactivator for the transcription factor CREB. Nature 370:223-226

9. Carlezon WAJr, Thome J, Olson VG et al (1998) Regulation of cocaine reward by CREB. Science 282:2272-2275

10. Dawson TM, Ginty DD (2002) CREB family transcription factors inhibit neuronal suicide. Nat Med 8:450-451

11. Herzig S, Long F, Jhala US et al (2001) CREB regulates hepatic gluconeogenesis through coactivator PGC-1. Nature 413:179183

12. Schwaninger M, Lux G, Blume R, Oetjen E, Hidaka H, Knepel W (1993) Membrane depolarization and calcium influx induce glucagon gene transcription in pancreatic islet cells through the cyclic AMP-responsive element. J Biol Chem 268:5168-5177

13. Dalle S, Longuet C, Costes S et al (2004) Glucagon promotes cAMP-response element-binding protein phosphorylation via activation of ERK1/2 in MIN6 cell line and isolated islets of Langerhans. J Biol Chem 279:20345-20355

14. Reddy UR, Basu A, Bannermann P, Ikegaki N, Reddy CD, Pleasure D (1999) ZPK inhibits PKA induced transcriptional activation by CREB and blocks retinoic acid induced neuronal differentiation. Oncogene 18:4474-4444

15. Docherty K, Clark AR (1994) Nutrient regulation of insulin gene expression. FASEB J 8:20-27

16. Schwaninger M, Blume R, Oetjen E, Knepel W (1993) The immunosuppressive drugs cyclosporin A and FK506 inhibit calcineurin phosphatase activity and gene transcription mediated through the cAMP-responsive element in a nonimmune cell line. Naunyn Schmiedebergs Arch Pharmacol 348:541-545

17. Schwaninger M, Blume R, Oetjen E, Lux G, Knepel W (1993) Inhibition of cAMP-responsive element-mediated gene transcription by cyclosporin A and FK506 after membrane depolarization. J Biol Chem 268:23111-23115

18. Holzman LB, Merritt SE, Fan G (1994) Identification, molecular cloning, and characterization of dual leucine zipper bearing kinase. J Biol Chem 269:30808-30817

19. Mata M, Merritt SE, Fan G, Yu GG, Holzman LB (1996) Characterization of dual leucine zipper-bearing kinase, a mixed lineage kinase present in synaptic terminals whose phosphorylation state is regulated by membrane depolarization via calcineurin. J Biol Chem 271:16888-16896

20. Kincaid RL, Giri PR, Higuchi S et al (1990) Cloning and characterization of molecular isoforms of the catalytic subunit of calcineurin using nonisotopic methods. J Biol Chem 265: 11312-11319

21. Krause A, Holtmann H, Eickemeier S et al (1998) Stressactivated protein kinase/Jun N-terminal kinase is required for interleukin (IL)-1-induced IL-6 and IL-8 gene expression in the human epidermal carcinoma cell line KB. J Biol Chem 273: 23681-23689 
22. Walton KM, Rehfuss RP, Chrivia JC, Lochner JE, Goodman RH (1992) A dominant repressor of cyclic adenosine 3',5'monophosphate (cAMP)-regulated enhancer-binding protein activity inhibits the cAMP-mediated induction of the somatostatin promoter in vivo. Mol Endocrinol 6:647-655

23. Sadowski I, Ptashne M (1989) A vector for expressing GAL4 (1-147) fusions in mammalian cells. Nucl Acids Res 17:7539

24. Oetjen E, Thoms KM, Laufer Y et al (2005) The immunosuppressive drugs cyclosporin $\mathrm{A}$ and tacrolimus inhibit membrane depolarization-induced CREB transcriptional activity at the coactivator level. Brit J Pharmacol 144:982-993

25. Bradford MM (1976) A rapid and sensitive method for the quantitation of microgram quantities of protein utilizing the principle of protein-dye binding. Anal Biochem 72:248-254

26. Merritt SE, Mata M, Nihalani D, Zhu C, Hu X, Holzman LB (1999) The mixed lineage kinase DLK utilises MKK7 and not MKK4 as substrate. J Biol Chem 274:10195-10202

27. Chawla S, Hardingham GE, Quinn DR, Bading H (1998) CBP: a signal-regulated transcriptional coactivator controlled by nuclear calcium and CaM kinase IV. Science 281:1505-1509

28. Ohneda K, Ee H, German M (2000) Regulation of insulin gene transcription. Semin Cell Dev Biol 11:227-233

29. Schwaninger M, Blume R, Krüger M, Lux G, Oetjen E, Knepel W (1995) Involvement of the Ca2+-dependent phosphatase calcineurin in gene transcription that is stimulated by cAMP through cAMP response elements. J Biol Chem 270:8860-8866

30. Dolmetsch RE, Pajvani U, Fife K, Spotts JM, Greenberg ME (2001) Signaling to the nucleus by an L-type calcium channelcalmodulin complex through the MAP kinase pathway. Science 294:333-339

31. Gomez E, Pritchard C, Herbert TP (2002) cAMP-dependent protein kinase and $\mathrm{Ca}^{2+}$ influx through L-type voltage-gated calcium channels mediate Raf-independent activation of extracellular regulated kinase in response to glucagon-like peptide-1 in pancreatic $\beta$-cells. J Biol Chem 277:48146-48151

32. Gallo KA, Johnson GL (2002) Mixed-lineage kinase control of JNK and p38 MAPK pathways. Nat Rev/Mol Cell Biol 3:663672

33. Fan G, Merrit SE, Kortenjann M, Shaw PE, Holzman LB (1996) Dual leucine zipper-bearing kinase (DLK) activates p46 ${ }^{\mathrm{SAPK}}$ and $\mathrm{p} 38^{\mathrm{mapk}}$ but not ERK2. J Biol Chem 271:2478824793

34. Nihalani D, Merritt S, Holzman LB (2000) Identification of structural and functional domains in mixed lineage kinase dual leucine zipper-bearing kinase required for complex formation and stress-activated protein kinase activation. J Biol Chem 275:7273-7279

35. Nihalani D, Meyer D, Holman LB (2001) Mixed linage kinasedependent JNK activation is governed by interactions of scaffold protein JIP with MAPK module components. EMBO J 20:3447-3458
36. Nihalani D, Wong HN, Holzman LB (2003) Recruitment of JNK to JIP and JNK-dependent JIP1 phosphorylation regulates JNK module dynamics and activation. J Biol Chem 278: 28694-28702

37. Xu Z, Kukekov NV, Greene LA (2003) POSH acts as a scaffold for a multiprotein complex that mediates JNK activation in apoptosis. EMBO J 22:252-261

38. Hu SC, Chrivia J, Gosh A (1999) Regulation of CBP-mediated transcription by neuronal calcium signaling. Neuron 22:799-808

39. Impey S, Fong AL, Wang Y et al (2002) Phosphorylation of CBP mediates transcriptional activation by neural activity and CaM Kinase IV. Neuron 34:235-244

40. See RH, Calvo D, Shi Y et al (2001) Stimulation of p300mediated transcription by the kinase MEKK1. J Biol Chem 276:16310-16317

41. Janknecht R, Nordheim A (1996) Regulation of the c-fos promoter by the ternary complex factor Sap-1a and its coactivator CBP. Oncogene 12:1961-1969

42. Yakel JL (1997) Calcineurin regulation of synaptic functionfrom ion channels to transmitter release and gene transcription. Trends Pharmacol Sci 18:124-134

43. Matsuda S, Moriguchi T, Koyasu S, Nishida E (1998) T lymphocyte activation signals for interleukin-2 production involve activation of MKK6-p38 and MKK7-SAPK/JNK signalling pathways sensitive to cyclosporin A. J Biol Chem 273: 12378-12382

44. Murat A, Pellieux C, Brunner HR, Pedrazzini T (2000) Calcineurin blockade prevents cardiac mitogen-activated protein kinase activation and hypertrophy in renovascular hypertension. J Biol Chem 275:40867-40873

45. De Windt LJ, Lim HW, Haq S, Force T, Molkentin JD (2000) Calcineurin promotes protein kinase $\mathrm{C}$ and c-Jun $\mathrm{NH}_{2}$-terminal kinase activation in the heart. J Biol Chem 275:13571-13579

46. Screaton RA, Conkright MD, Katoh Y et al (2004) The CREB coactivator TORC2 functions as a calcium- and cAMPsensitive coincidence detector. Cell 119:61-74

47. Chang L, Karin M (2001) Mammalian MAP kinases signalling cascades. Nature 410:37-40

48. Evans JL, Goldfine ID, Maddux BA, Grodsky GM (2002) Oxidative stress and stress-activated signaling pathways: a unifying hypothesis of type 2 diabetes. Endocr Rev 23:599-622

49. Namgaladze D, Hofer HW, Ullrich V (2002) Redox control of calcineurin by targeting the binuclear $\mathrm{Fe}(2+)-\mathrm{Zn}(2+)$ center at the enzyme active site. J Biol Chem 277:5962-5969

50. Waeber G, Delplanque J, Bonny C et al (2000) The gene MAPK8IP1, encoding islet-brain-1, is a candidate for type 2 diabetes. Nat Genet 24:291-295

51. Ling Z, Van de Casteele M, Dong J et al (2003) Variations in IB1/JIP1 expression regulate susceptibility of beta-cells to cytokine-induced apoptosis irrespective of c-Jun $\mathrm{NH}_{2}$-terminal kinase signaling. Diabetes 52:2497-2502 